\title{
Is hospitalization necessary in isolated traumatic sternal fractures?
}

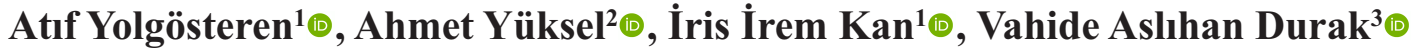 \\ ${ }^{1}$ Department of Cardiovascular Surgery, Uludă̆ University School of Medicine, Bursa, Turkey \\ ${ }^{2}$ Department of Cardiovascular Surgery, Abant İzet Baysal University School of Medicine, Bolu, Turkey \\ ${ }^{3}$ Department of Emergency Medicine, Uludağ University School of Medicine, Bursa, Turkey
}

\begin{abstract}
Objectives: Clinical characteristics, follow-up and treatment outcomes of patients with isolated traumatic sternal fracture were presented and our clinical experiences on these patients were shared.

Methods: Between January 2010 and December 2017, a total of 87 patients with isolated traumatic sternal fracture who were admitted to the emergency department and were hospitalized, were included in this observational cohort study. Medical data of these patients were collected from hospital records and then were retrospectively reviewed.

Results: There were $65(74.7 \%)$ male and $22(25.3 \%)$ female patients. Mean age was $42.4 \pm 13.7$ years (range: 17-83). The most common etiological reason was traffic accident in vehicle. Sternal fractures were localized at corpus in $64(73.6 \%)$ patients and at manubrium in $23(26.4 \%)$ patients. The most common concomitant pathology was rib fracture with a ratio of $23 \%$ (20 patients). Mean length of hospital stay of patients was 3.1 \pm 0.8 days. During the hospitalization period, no evidence of cardiac injury was observed in any patient.

Conclusions: In view of rising healthcare costs and increasing demand for acute hospital and intensive care beds, it is crucial to determine hospitalization criteria for cases with traumatic sternal fracture. We believe that the hospitalization is not necessary in isolated traumatic sternal fractures where there is no other major injury. Keywords: Sternal fracture, trauma, treatment, hospitalization
\end{abstract}

$\mathrm{S}^{\prime-1}$ ternal fractures are encountered with a $3 \%$ to $8 \%$ prevalence in blunt thoracic trauma cases [1]. These fractures are seen frequently in passengers in the front seats of vehicles involved in accidents are increasingly observed in recent years since the compulsory usage of safety belts $[2,3]$. Pain in the sternal area and extreme sensibility on palpation are the most frequent symptoms and their presence should prompt suspicion of a sternal fracture. Sternal fractures are usually on a transverse direction and usually upper and mid portion of the sternum is involved. Physical examination reveals sensibility at the fracture site, eccyhymosis and crepitation on palpation of the injured area. Usually a lateral chest X-ray is sufficient for radiological confirmation of a suspected sternal fracture. Thoracic CT which is a more sensitive radiological technique is resorted when the diagnosis is not certain or when accompanying pathologies are anticipated [4]. The localization and structural properties of the sternum lends itself as an important barrier for the vital organs like the heart, great vessels and the lungs. This said the injuries to these vital

Address for correspondence: Ahmet Yüksel, MD., Assistant Professor, Abant İzet Baysal University School of Medicine, Department of Cardiovascular Surgery, Gölköy Campus, 14280,Bolu, Turkey.E-mail: ahmetyuksel@ibu.edu.tr 
organs due to sternal fractures are more important than the sternum fracture itself.

Isolated sternum fracture is by definition a traumatic sternal fracture without accompanying cranial fracture, intracranial hemorrhage, hemothorax, pneumothorax, intra-abdominal organ damage or any other kind of major injury $[5,6]$. There is no universally agreed upon consensus regarding the evaluation of the sternum fractures nor on the algorithm of the treatment of them [7]. Naturally the evaluation and treatment is dictated by each center's experience and their equipment which leads to a variety of approaches among different centers.

In this study, patients who were admitted to the emergency department with sternum fracture and hospitalized were analyzed and their clinical and demographic features, and follow up and treatment outcomes were presented, our clinical experiences with this patient group were shared. Also, in view of our experience with this patient population that we had hospitalized, the merits of hospitalization were discussed.

\section{METHODS}

Over an 8-year period between January 2010 and December 2017, a total of 87 patients with isolated sternum fractures who were admitted to the emergency department of a tertiary referral center in Turkey and later hospitalized are included in this retrospective observational cohort study. Patients who were diagnosed as isolated sternum fractures after physical examination, laboratory and radiological studies at the emergency room were admitted to the Cardiovascular Surgery intensive care unit and ward where the patients were observed and treated. Emergency room registrations, forensic registrations and clinical documents were used to determine the patients' age, gender, type of the trauma, localization of the fracture, symptoms, employed diagnostic tools and treatment modalities, treatment outcomes, hospitalization duration and other minor pathologies accompanying the traumatic sternal fracture. The patients' hemodynamic parameters as arteriel blood pressure and heart rate were monitorized and electrocardiogram (ECG) monitorization was performed, furthermore cardiac damage indicators such as creati- nine kinase $(\mathrm{CK})$, creatinine kinase-myocardial band (CK-MB) and troponin-I levels were all periodically measured. Patients with suspected cardiac damage were evaluated with echocardiography. The treatment mainly consisted of the alleviation of pain, bed rest and treatment of associated other diseases if present. Patients with hypovolemic or hemorrhagic shock, multi-organ trauma, a history of cardiac disease such as coronary artery disease and congestive heart failure and had severe comorbid conditions (malignancy, hepatic and renal insufficiency, etc.) were excluded from the study.

The study protocol was approved by the institutional ethics committee, and the study was conducted in accordance with the principles of the Declaration of Helsinki.

\section{Statistical Analysis}

All statistical analysis of our study was done using Statistical Package for Social Sciences (SPSS) program (version 20.0, SPSS, Chicago, Illinois, USA). Continuous variables were shown as average \pm standard deviation, while categorical variables were expressed as frequency and percentage.

\section{RESULTS}

The average age of patients was $42.4 \pm 13.7$ years, with an age range of between 17 and 83 years. Sixty five $(74.7 \%)$ of the patients were male, while 22 $(25.3 \%)$ of the patients were female. When the type of trauma and etiological causes of the sternum fractures were evaluated, the most common cause was found to be in-vehicle traffic accidents with $44(50.6 \%)$ cases (Table 1). The remaining causes were falling in 30 $(34.5 \%)$ cases, workplace accidents in $5(5.7 \%)$ cases, animal induced trauma in $4(4.6 \%)$ cases, vehicle induced trauma in $2(2.3 \%)$ cases and assault (battering) again in $2(2.3 \%)$ cases. While all patients had pain and sensitivity with palpation on sternum, only $19(21.8 \%)$ patients displayed an eccyhymosis and/or crepitation with palpation. When the patients were evaluated radiologically; fractures were seen at the corpus sterni in 64 (73.6\%) patients (Fig. 1) and at the manubrium of sternum in $23(26.4 \%)$ cases. The most frequent pathology accompanying sternal fracture was rib fracture which was detected in in $20(23 \%)$ cases. 


\section{Table 1. Clinical characteristics of patients}

\begin{tabular}{lc}
\hline Characteristics & Data \\
\hline Age (years) (mean \pm SD) & $42.4 \pm 13.7$ \\
Gender, n (\%) & \\
\hline Male & $65(74.7)$ \\
\hline Female & $22(25.3)$ \\
\hline Etiological factors, $\mathrm{n}(\%)$ & \\
\hline In-vehicle traffic accident & $44(50.6)$ \\
\hline Falling & $30(34.5)$ \\
\hline Workplace accident & $5(5.7)$ \\
\hline Animal induced trauma & $4(4.6)$ \\
Vehicle induced trauma & $2(2.3)$ \\
Assault & $2(2.3)$ \\
\hline Fracture localization, $\mathrm{n}(\%)$ & $64(73.6)$ \\
\hline Corpus sterni & $23(26.4)$ \\
\hline Manubrium sterni
\end{tabular}

Average length of hospital stay was $3.1 \pm 0.8$ days. During the hospitalization, none of the patients displayed hemodynamic instability, major changes on ECG, cardiac enzymes levels, and echocardiographic finding to indicate cardiac injury.

\section{DISCUSSION}

The most important finding of this study was that in our study population none of the patients with isolated traumatic sternal fracture had apparent traumatic cardiac injury. Sternal fracture presents itself in a conscious patient with direct or indirect pain over the sternum. Physical examination may reveal irregularity and/ or step-up deformity of the sternum on palpation. Eccyhmosis, hematoma and contusion may be

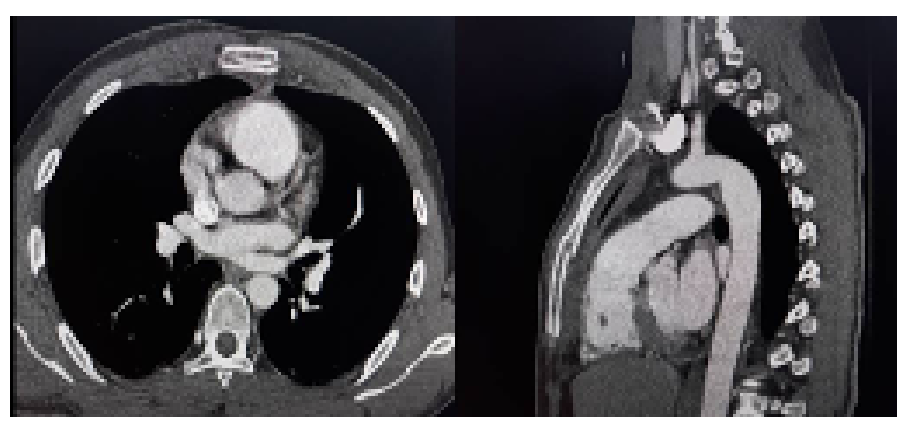

Fig. 1. Fracture on corpus sterni observed in inspection. Posterior-anterior, lateral and oblique sternum $\mathrm{x}$-rays are essential in cases of suspected sternal traumas $[8,9]$. In our study population $65(74.7 \%)$ patients were diagnosed solely with direct radiography. In cases with uncertain diagnosis and/or suspected additional pathologies, computed tomography was performed and $22(25.3 \%)$ patients in whom sternal fracture could not be verified by direct radiography were diagnosed as such.

Treatment of patients with sternal fracture consists of bedrest in supine position, pain relief and respiratory physiotherapy. Pain can persist for six weeks. Complete sternal stabilization with conservative management generally ensues in two months [10]. Sternal fracture rarely necessitates surgical treatment. If sternal stability has been disrupted sternal fixation is required. In some patients in which severe paradoxical respiration evolves stabilization can be performed surgically. Due to prominent visible compression surgical repair may be warranted on cosmetic grounds [11-13]. In any case no patient in our study required surgical stabilization nor correction. We recommended only bedrest and analgesic therapy to our patients on discharge.

Pericardial tamponade, mediastinal hematoma and abscess, osteomyelitis due to delayed healing can be seen in sternal fracture. Furthermore patients should be carefully evaluated for myocardial contusion and pulmonary parenchymal injuries. Upon admission ECG ,CK CK-MB values of the patients should be evaluated. In cases with suspected myocardial injury, the most convenient and time sparing diagnostic method is echocardiographic assessment $[1,14-16]$. In our study group no patient had myocardial damage.

Duration of hospitalization in sternal fracture is related rather to the associated traumatic pathologies than to the sternal fracture itself. Isolated sternal fracture generally has a benign course and usually heals on its own. Analgesic therapy and respiratory physiotherapy are thought to be sufficient in isolated SF. If accompanying intrathoracic pathologies are present these pathologies determine the prognosis of the patients $[2,5,15-18]$.

\section{Limitations}

The most important limitation of our study was that it was designed as a retrospective data analysis with a relatively small sample size in a single-center. 
Another important limitation was the lack of the follow-up data.

\section{CONCLUSION}

The results of our study have demonstrated that the isolated sternum fractures are benign entity. Considering the ever increasing health care expenses and the demand for the hospital beds both of wards and intensive care units; establishing the criteria for hospitalization of patients with traumatic sternum fractures is very important. We believe that in patients diagnosed as isolated sternum fracture without any coexisting major injury in the emergency room do not warrant hospitalization. We suggest that this patient group can be treated at home with medical recommendations and organizing home therapy.

\section{Conflict of interest}

The authors disclosed no conflict of interest during the preparation or publication of this manuscript.

\section{Financing}

The authors disclosed that they did not receive any grant during conduction or writing of this study.

\section{REFERENCES}

1. Brookes J, Dunn R, Rogers I. Sternal fractures: a retrospective analysis of 272 cases. J Trauma 1993;35:46-54.

2. Athanassiadi K, Gerazounis M, Moustardas M, Mataxas E. Sternal fractures: retrospective analysis of 100 cases. World J Surg 2002;26:1243-6.

3. Turhan K, Çakan A, Özdil A, Çağırıcı U. Traumatic sternal fractures: diagnosis and management. Ege Tip Dergisi
2010;49:107-11.

4. Acipayam A. Our experiences in traumatic sternal fractures and treatment. KSU Tip Fak Derg 2016;11:33-5.

5. Guska S, Pilav I, Musanovic S. Clinical significance of isolated sternal fracture. Med Arh 2010;64:17-21.

6. Dua A, McMaster J, Desai PJ, Desai SS, Kuy S, Mata M, et al. The association between blunt cardiac injury and isolated sternal fracture. Cardiol Res Pract 2014;2014:629687.

7. Wedde TB, Quinlan JF, Khan A, Khan HJ, Cunningham FO, McGrath JP. Fractures of the sternum: the influence of noninvasive cardiac monitoring on management. Arch Orthop Trauma Surg 2007;127:121-3.

8. Khoriati AA, Rajakulasingam R, Shah R. Sternal fractures and their management. J Emerg Trauma Shock 2013;6:113-6.

9. Engin G, Yekeler E, Güloğlu R, Acunaş B, Acunaş G. US versus conventional radiography in the diagnosis of sternal fractures. Acta Radiol 2000;41:296-9.

10. Klei DS, de Jong MB, Öner FC, Leenen LPH, van Wessem KJP. Current treatment and outcomes of traumatic sternal fractures-a systematic review. Int Orthop 2019;43:1455-64.

11. Molina JE. Evaluation and operative technique to repair isolated sternal fractures. J Thorac Cardiovasc Surg 2005;130:445-8.

12. Harston A, Roberts C. Fixation of sternal fractures: a systematic review. J Trauma 2011;71:1875-9.

13. Ata Y, Aydın U, As AK, Özsin KK, Findık O, Türk T. Sternal cable wires for sternal closure in moderately or extremely obese patients undergoing cardiac surgery. Eur Res J 2018;4:308-13. 14. Wiener Y, Achildiev B, Karni T, Halevi A. Echocardiogram in sternal fracture. Am J Emerg Med 2001;19:403-5.

15. Kumbasar U, Tokat AO, Karasu S, Çakmak H, Tokat S, Uzun HA, et al. Sternal fractures: retrospective analysis of 55 cases. Ankara Üniversitesi Tıp Fakültesi Mecmuası 2012;65:125-8. 16. Uluşan A, Karakurt Ö. Cardiac findings of sternal fractures due to thoracic trauma: a five-year retrospective study. Ulus Travma Acil Cerrahi Derg 2018;24:249-54.

17. Korkmaz UTK, Taşlıgıl C, Bayraktarlı RY, Kısaoğlu O. Left axillary artery pseudoaneurysm developing 1 year after a stab wound. Med J Islamic World Acad Sci 2018;26:23-5.

18. Racine S, Émond M, Audette-Côté JS, Le Sage N, Guimont $\mathrm{C}$, Moore L, et al. Delayed complications and functional outcome of isolated sternal fracture after emergency department discharge: a prospective, multicentre cohort study. CJEM 2016;18:349-57. 